\title{
Clinical applications of somatostatin analogs for growth hormone-secreting pituitary adenomas
}

This article was published in the following Dove Press journal:

Patient Preference and Adherence

6 January 2014

Number of times this article has been viewed

\author{
Ji-wen Wang ${ }^{1,2}$ \\ Ying $\mathrm{Li}^{3}$ \\ Zhi-gang Mao ${ }^{1,2}$ \\ Bin $\mathrm{Hu}^{1,2}$ \\ Xiao-bing Jiang ${ }^{1,2}$ \\ Bing-bing Song ${ }^{4}$ \\ Xin Wang ${ }^{4}$ \\ Yong-hong $\mathrm{Zhu}^{4}$ \\ Hai-jun Wang ${ }^{1,2}$ \\ 'Department of Neurosurgery \\ and Pituitary Tumor Center, The \\ First Affiliated Hospital, Sun Yat- \\ sen University, ${ }^{2} \mathrm{Key}$ Laboratory of \\ Pituitary Adenoma in Guangdong \\ Province, ${ }^{3}$ State Key Laboratory \\ of Ophthalmology, Zhongshan \\ Ophthalmic Center, Sun Yat-sen \\ University, ${ }^{4}$ Department of Histology \\ and Embryology, Zhongshan School \\ of Medicine, Sun Yat-sen University, \\ Guangzhou, People's Republic of \\ China
}

Correspondence: Hai-jun Wang: Department of Neurosurgery and Pituitary Tumor Center, The First Affiliated Hospital, Sun Yat-sen University, No 58, Zhongshan Road 2, Guangzhou 510080, People's Republic of China

Emailwzwxr_1995@aliyun.com

Yong-hong Zhu

Department of Histology and

Embryology, Zhongshan School of

Medicine, Sun Yat-sen University, No. 74,

Zhongshan Road 2, Guangzhou 510080 ,

People's Republic of China

Email zhuyongh@mail.sysu.edu.cn
Abstract: Excessive growth hormone $(\mathrm{GH})$ is usually secreted by GH-secreting pituitary adenomas and causes gigantism in juveniles or acromegaly in adults. The clinical complications involving cardiovascular, respiratory, and metabolic systems lead to elevated morbidity in acromegaly. Control of serum GH and insulin-like growth factor (IGF) 1 hypersecretion by surgery or pharmacotherapy can decrease morbidity. Current pharmacotherapy includes somatostatin analogs (SAs) and GH receptor antagonist; the former consists of lanreotide Autogel (ATG) and octreotide long-acting release (LAR), and the latter refers to pegvisomant. As primary medical therapy, lanreotide ATG and octreotide LAR can be supplied in a longlasting formulation to achieve biochemical control of GH and IGF-1 by subcutaneous injection every 4-6 weeks. Lanreotide ATG and octreotide LAR provide an effective medical treatment, whether as a primary or secondary therapy, for the treatment of GH-secreting pituitary adenoma; however, to maximize benefits with the least cost, several points should be emphasized before the application of SAs. A comprehensive assessment, especially of the observation of clinical predictors and preselection of SA treatment, should be completed in advance. A treatment process lasting at least 3 months should be implemented to achieve a long-term stable blood concentration. More satisfactory surgical outcomes for noninvasive macroadenomas treated with presurgical SA may be achieved, although controversy of such adjuvant therapy exists. Combination of SA and pegvisomant or cabergoline shows advantages in some specific cases. Thus, an individual treatment program should be established for each patient under a full evaluation of the risks and benefits.

Keywords: GH-secreting pituitary adenoma, somatostatin analogs, lanreotide ATG, octreotide LAR, growth hormone, insulin-like growth factor 1

\section{Introduction}

Pituitary adenoma accounts for $15 \%$ of primary intracranial tumors. ${ }^{1}$ Growth hormone (GH)-secreting pituitary adenoma had a World Health Organization 2000-standardized incidence rate of 0.34 per 100,000 . GH-secreting pituitary adenoma is the only type of adenoma that shows a male-dominant tendency, although the difference due to sex is not significant. ${ }^{2}$ Excessive GH secretion can cause gigantism in juveniles, because of the active epiphyseal growth plates that allow linear growth, or acromegaly in adults. ${ }^{3}$ The data of incidence, clinical presentations, and treatment strategy for patients with gigantism is limited, owing to its lower incidence rate relative to that of acromegaly; 3,4 however, similar organomegaly and deteriorating glucose tolerance have been found in follow-up patients ${ }^{5}$ with either acromegaly or gigantism. ${ }^{6}$ Recent studies have shown that therapy for acromegaly was also successful and safe in patients with gigantism. ${ }^{3,6-8}$ 
Thus, in this review, we mainly summarize the clinical application of somatostatin analogs (SAs) for acromegaly, with the related data of gigantism being discussed in the last part of this review.

\section{Background Clinical manifestation}

Acromegaly and gigantism usually manifest as coarsened facial features and hypertrophy of hands, feet, and soft tissue. ${ }^{9}$ The characteristic clinical manifestations mainly derive from local mass effects and biological function of excessive secreted GH. First, the compression of local nerves causes temporal hemianopia of one or both eyes, ophthalmoplegia, and ptosis. ${ }^{10}$ Further, the elevated intrasellar pressure could shut down the hypophyseal portal vein, which carries regulatory hormones from the hypothalamus, therefore leading to hypopituitarism and moderate hyperprolactinemia. ${ }^{11}$ Second, the excessive secretion of GH and insulin-like growth factor (IGF) 1 will lead to severe complications in the cardiovascular, respiratory, metabolic, skeletal, and integumentary systems, which subsequently increases the risk of death significantly. ${ }^{12}$ Cardiovascular complications, especially myocardial infarction, are the most common cause of death, while malignancy and cerebrovascular events occupy the second and third most common causes of mortality, respectively. ${ }^{13}$ Although the biologic changes are usually more concerning, the mass effects of GH-secreting pituitary adenoma should not be ignored. Temporal hemianopia, ophthalmoplegia, ptosis, and hypopituitarism affect the quality of life in patients with pituitary adenoma to a variable extent, while hemorrhage in giant pituitary adenoma can lead to acute pituitary apoplexy, which is a life-threatening condition.

\section{Treatment goals and strategies}

A previous study has indicated that $\mathrm{GH}<2.5 \mathrm{ng} / \mathrm{mL}$, younger age, and shorter duration of disease are the independent determinants of longer survival, ${ }^{1}$ so the indication of medical intervention should be confirmed after diagnosis. ${ }^{14}$ Sometimes, the serum GH and IGF-1 show a divergent relationship; ${ }^{15}$ hence, if both the random serum $\mathrm{GH}<2.5 \mathrm{ng} / \mathrm{mL}$ and IGF-1 normalization for age and sex can be achieved, patients can be expected to have nearly the same duration of life as unaffected persons. ${ }^{16}$

The current therapies of GH-secreting pituitary adenoma are surgery, medical treatment, and radiotherapy. ${ }^{14}$ The main aim of these approaches is to remove the mass that compresses its surroundings and to normalize serum GH and IGF-1 levels. ${ }^{12,16}$ Although different treatments have their specific advantages and disadvantages, the ultimate goal of the treatment is to reduce the mortality and morbidity in acromegaly and gigantism patients. Transsphenoidal surgery is an optimal choice for microadenomas and noninvasive macroadenomas, especially for the resolution of compression. The biological control rates of GH and IGF-1 can reach 75\%-95\% in microadenomas and 40\%-68\% in noninvasive macroadenomas. ${ }^{14}$ Patients with a tumor less than $2 \mathrm{~cm}$ and random serum $\mathrm{GH}$ level less than $50 \mathrm{ng} / \mathrm{mL}$ show higher remission rates after surgery; ${ }^{16}$ however, about $40 \%-60 \%$ of macroadenomas are unable to be cured by surgery alone because of the invasion to cavernous sinus or third ventricle. ${ }^{14}$ Although complete excision of such macroadenomas is impossible, surgical debulking could enhance the effect of SA. ${ }^{17,18}$ For medical therapy, SA, GH receptor antagonist (GHRA), and dopamine agonist (DA) are available. SAs are the strongly recommended medical treatment for $\mathrm{GH}$-secreting pituitary adenoma when surgery fails to achieve GH and IGF-1 normalization. ${ }^{14}$ Radiation therapy for GH-secreting pituitary adenoma is recommended as a third-line treatment to control excessive GH or IGF-1 when surgery and medical treatment are unsuccessful. ${ }^{14}$ The main limitation of radiation therapy is safety, considering the high occurrence rate of hypopituitarism. ${ }^{19}$

\section{Overview of medical treatment}

Patients with GH-secreting pituitary adenoma receiving SA treatment for more than 3 months show a reduced tumor volume and normalized serum GH and IGF-1. ${ }^{20}$ There are two efficient, long-lasting formulations of SA, octreotide long-acting release (LAR) and lanreotide Autogel ([ATG]; Ipsen, Paris, France), which replace lanreotide slow release (SR) because of their higher rate of response..$^{21-25}$ They are equivalent in the control of biological markers and tumor volume. ${ }^{26,27}$ Although GHRA shows high efficacy in improving quality of life and controlling IGF-1, tumor shrinkages are not observed in most patients. ${ }^{28}$ Also, the guidelines of Melmed et al limit the strong recommendation of GHRA in the case of persistently elevated IGF-1 despite a maximal dose of SA treatment. ${ }^{14}$ Recent data show that a combination of SA and GHRA is effective and can greatly reduce the costs of medical therapy. ${ }^{29,30}$ As per the findings of Abs et al in 1998, there was limited effect in monotherapy with cabergoline for acromegaly. ${ }^{31}$ A recent meta-analysis, however, conducted by Sandret et al, who systematically reviewed all trials of cabergoline therapy for acromegaly, suggested that cabergoline could achieve better results than expected, either alone or in combination with SA. ${ }^{32}$ 
In this review, we will focus on the clinical predictors, preselection of SA, and the benefits from the stable blood concentration. The controversy of presurgical SA treatment and the different strategies of primary or secondary medical treatment will also be discussed (Table 1).

\section{Optimization of SA treatment Clinical predictors of medical treatment}

As mentioned above, it is important to reduce both GH and IGF-1 to normal levels; ${ }^{16}$ however, patients with GH-secreting pituitary adenoma show different susceptibilities to SA treatment. The full response to a 12-month SA treatment includes control of GH/IGF- 1 and more than $20 \%$ tumor shrinkage in primary treatment or no tumor remnant on magnetic resonance imaging, while a partial response means that a more than $50 \%$ decrease of GH and/or failure to control IGF-1 levels with or without more than $20 \%$ tumor shrinkage is obtained (Table 2). ${ }^{33}$ Taking the cost of SA treatment into account, it is necessary to access the benefit before the treatment. Clinical predictors of SA treatment that are already known include tumor size, serum GH before treatment, and the density of the somatostatin receptor (SSTR). ${ }^{34-36}$ Related studies have shown that, in patients with serum $\mathrm{GH}>16.7 \mathrm{ng} / \mathrm{mL}$ or $20 \mathrm{ng} / \mathrm{mL}$, SA treatment is unsatisfactory for GH/IGF-1 control and tumor shrinkage. ${ }^{34,35}$ In the study by Colao et al, small, noninvasive tumor with low serum GH demonstrated a better response to lanreotide ATG. ${ }^{37}$ According to the results of molecular biological researches, SSTRs, on which somatostatin binds, have five subtypes, of which SSTR 2 and 5 are predominantly expressed on the cell membrane of GH-secreting pituitary tumor cells. ${ }^{38}$ High-density SSTR distribution on the tumor cell may result in a promising response to SA treatment; ${ }^{36,38}$ however, Bertherat et al showed that loss of SSTR could not explain the continued partial suppression of GH induced by SA and that the density of SSTR was poorly related to SA

Table I Main content of this review

Optimization of somatostatin analog treatment

Different strategies Drug combinations New somatostatin analogs

Treatment of gigantism

Note: alpsen, Paris, France.
Table 2 Definition of response to somatostatin analog treatment (12 months)

\begin{tabular}{|c|c|c|}
\hline & Biochemical response & Tumor response \\
\hline $\begin{array}{l}\text { Full } \\
\text { response }\end{array}$ & $\begin{array}{l}\text { Random serum } \\
\mathrm{GH}<2.5 \mathrm{ng} / \mathrm{mL} \\
\text { and a normal IGF-I } \\
\text { for age and sex }\end{array}$ & $\begin{array}{l}>20 \% \text { tumor shrinkage } \\
\text { in patients with primary } \\
\text { treatment; stabilization } \\
\text { of tumor remnant or no } \\
\text { recurrence in patients treated } \\
\text { with secondary treatment }\end{array}$ \\
\hline $\begin{array}{l}\text { Partial } \\
\text { response }\end{array}$ & $\begin{array}{l}\text { Significant decrease } \\
(>50 \%) \text { of } \mathrm{GH} \text { level and/or } \\
\text { failure to control IGF-I levels }\end{array}$ & $\begin{array}{l}\text { With or without tumor } \\
\text { shrinkage }\end{array}$ \\
\hline Resistance & $\begin{array}{l}\text { Nonsignificant decrease } \\
\text { of GH and IGF-I levels with } \\
\text { no achievement of control }\end{array}$ & $\begin{array}{l}\text { No tumor shrinkage in patients } \\
\text { treated first-line or increase in } \\
\text { tumor size in any patient }\end{array}$ \\
\hline
\end{tabular}

Notes: OGTT is not recommended for monitoring therapeutic response during SA treatment. Data from Melmed et al. ${ }^{14}$ Republished with modification in full response of Biochemical response and with permission of Endocrine Society, from Resistance to somatostatin analogs in acromegaly. Colao A, Auriemma RS, Lombardi G, Pivonello R. 20I I;32(2):247-27I. ${ }^{33}$ Permission conveyed through Copyright Clearance Center, Inc. Abbreviations: GH, growth hormone; IGF-I, insulin-like growth factor I; OGTT, oral glucose tolerance test.

treatment in vivo. ${ }^{39}$ In other words, factors apart from those mentioned also play a role in influencing SA treatment results. Several factors have been found to affect susceptibility to lanreotide and octreotide. For example, in female patients with hypogonadism, oral estrogens together with SA could facilitate better IGF-1 reduction compared with SA monotherapy. ${ }^{40}$ In addition to this, elderly people who show obvious cardiovascular or respiratory complications at diagnosis are more sensitive to SA treatment. ${ }^{41}$

\section{Preselection before medical treatment}

With different responses to SA treatment, patients with GHsecreting pituitary adenoma need preselection before the medical treatment. To predict the long-term response to SA treatment in patients with GH-secreting pituitary adenoma, the acute octreotide suppression test and ${ }^{111}$ In-pentetreotide scintigraphy are applied clinically. ${ }^{42-44}$ The acute octreotide test involves the use of subcutaneous Sandostatina (Sandoz, Milano, Italy) 50/100 $\mu \mathrm{g}$ to suppress the secretion of GH. Serum GH is assayed before (30 minutes, 15 minutes, 5 minutes) and after (hourly intervals for 6 hours) the sandostatina treatment. ${ }^{42}$ In the earliest study of the acute octreotide test, Lamberts et al found a close relationship between the mean serum GH measured 2-6 hours after a subcutaneous $50 \mu \mathrm{g}$ sandostatina administration and the mean 24-hour serum GH after a 96-week sandostatina treatment. ${ }^{44}$ Therefore, they hypothesized that the measurement of serum GH after an acute administration of $50 \mu \mathrm{g}$ sandostatina might be a good method for dose adjustment; ${ }^{44}$ however, the results differed in other studies. Colao et al, in 1996, conducted a similar study with octreotide subcutaneous $100 \mu \mathrm{g}$ for suppression, and the 
data showed that the acute test could not determine whether the patients might respond to the long-term treatment or not. ${ }^{42}$ With the use of depot long-acting somatostatin in clinic, the current standard for judging the response to SA treatment is stricter, and the value of the acute octreotide suppression test in predicting the long-term SA treatment response needs reassessment. Furthermore the criterion for the acute octreotide test response affects the results. In a study by Karavitaki, the data showed that, when the criterion of $\mathrm{GH}<2 \mathrm{ng} / \mathrm{mL}$ was adopted in the acute octreotide test, the sensitivity, specificity, positive predictive value, and negative predictive value of safe serum $\mathrm{GH}$ were $92 \%, 67 \%, 92 \%$, and $67 \%$, respectively, for the 6-month lanreotide therapy and $100 \%, 80 \%, 94 \%$, and $100 \%$, respectively, for the 6-month octreotide LAR therapy; ${ }^{42}$ however, the results of IGF-1 normalization were not satisfied. ${ }^{43}$ In a metaanalysis by Freda et al, the authors summarized the efficacy of two SA treatments and found that preselection was a positive predictor for IGF-1 and tumor shrinkage but not for serum GH. ${ }^{45}$ Although the abovementioned studies demonstrated varying results, the acute octreotide test showed its advantages in the prediction of long-acting SA treatment response, especially for sensitivity, which means that patients who respond to the acute octreotide test would be more likely to benefit from long-acting SA treatment.

In the preselection procedure using ${ }^{111}$ In-pentetreotide scintigraphy, related data show discrepant results. ${ }^{42,46-48}$ Plöckinger et al found that ${ }^{111}$ In-pentetreotide could be taken by pituitary adenoma cells regardless of the immunohistological subtypes, ${ }^{46}$ although the pentetreotide was expected to combine with SSTR. However, the small numbers of patients, lack of long-term follow-up, and failure to fulfill the current criterion of response to SA treatment in the earlier study means that preselection by

${ }^{111}$ In-pentetreotide scintigraphy is not widely used.

\section{Achieving a long-term stable blood concentration}

Lanreotide ATG itself is a sustained-release profile, lanreotide ATG shows a half-life of 22 days and residence time of 30-32 days for a 40/60 mg single dose. ${ }^{49}$ The mean steady-state serum concentration of 3.82, 5.69, $7.69 \mathrm{ng} / \mathrm{mL}$ were obtained in about 84 days following four doses of 60,90 , and $120 \mathrm{mg}$ ATG every 4 weeks, respectively, in patients with acromegaly. ${ }^{50}$ For octreotide LAR, the time to reach maximum drug concentration was 22 days for octreotide $20 \mathrm{mg}$ and 12.6 days for $60 \mathrm{mg}$, while the steady state of long-acting octreotide $20 \mathrm{mg}$ after three doses with 28-day intervals showed a mean concentration, minimum concentration, and maximum concentration of $1,216,1,065$, and $1,585 \mathrm{pg} / \mathrm{mL}$, respectively, and that the concentration was maintained at a consistent level during the dose intervals. ${ }^{51}$ Thus, to obtain a maximal and lasting clinical benefit, the SA treatment schedule of at least three to four doses with a 4-week interval is suggested. Such a treatment schedule was adopted in earlier studies concerning the effect of SA. Furthermore, longer treatment duration may bring higher response rates and better symptomatic improvements as outlined in the guidelines of Melmed et al. ${ }^{14}$ In recent studies, the observation of serum GH, IGF-1, and tumor shrinkage was performed after a long-term treatment of no less than 12 months, ${ }^{22,52,53}$ in which a better biochemical marker response and more obvious tumor shrinkage was achieved compared with after a 3-month treatment. ${ }^{21,53}$ Besides the increased percentage of patients who achieved safe serum GH and normalized IGF-1, the vascular, cardiac, and sleep parameters were improved with 6-month ATG treatment. ${ }^{54}$

\section{Clinical use in presurgical period and impact on surgery}

The main purpose of presurgical application of SA treatment is to remit the complications involving cardiovascular, respiratory, and, probably, metabolic systems to further decrease the anesthetic and perioperative risks ${ }^{54,55}$ and to decrease serum GH and IGF-1 levels and reduce tumor volume, which possibly leads to higher rates of total tumor resection. ${ }^{14}$ Cardiovascular complications are the major cause of acromegaly morbidity. ${ }^{12}$ Longer duration of disease activity and older age may lead to a higher risk during the perioperative period. Therefore, though such negative events were not proven, in the study of Seidman et al, to be markedly higher in active acromegaly than in controls, ${ }^{56}$ it is still worthwhile to emphasize the benefit of cardiovascular control during and after surgery, ${ }^{55}$ since the presurgical usage of SA has been demonstrated to result in decreased complication rates and shortened durations of hospitalization. ${ }^{57}$ Because of the varied durations of presurgical application of SA among studies, ${ }^{55,57,62,64,65,70,78}$ however, the potential cost benefit needs to be further assessed. The improvements in cardiovascular function could be achieved after a single dose of lanreotide, ${ }^{58}$ whereas, in the study of Annamalai et al,a 6-month treatment might be needed. ${ }^{54}$ As for respiratory complications, which mainly refer to change of lung volumes and the ventilation/ perfusion relationship, long-term SA treatment could reduce their occurrence. ${ }^{12,14}$ Nevertheless, the adverse respiratory events caused by intubation difficulty during anesthesia, derived from laryngeal and pharyngeal soft tissue hypertrophy or vocal cord swelling, could not be prevented by presurgical SA treatment. ${ }^{55,56}$ For metabolic complications, 
there is no report suggesting that metabolic complications can cause severe perioperative problems in acromegaly, although patients with uncontrolled blood sugar levels were detected in $30 \%$ in acromegaly. ${ }^{12}$ In a previous report, diabetic patients were shown to be at increased risk for poor wound healing and susceptibility to infection; ${ }^{59}$ therefore, the control of blood sugar might bring benefits for acromegaly patients who are prepared for surgery. ${ }^{55}$ In a study of octreotide by Colao et al, 6-month SA treatment decreased the insulin demand in patients receiving an insulin treatment and normalized the blood glucose in patients taking oral glucose control drugs. ${ }^{57}$ Similar studies of lanreotide were also conducted, and a stable blood glucose status could be achieved. ${ }^{60,61}$

Controversy persists among neurosurgeons regarding whether presurgical SA treatment could lead to a significant improvement of total resection of radical operation. ${ }^{55,57,62-72}$ Surgery provides the biochemical cure of normalized IGF-1 in $75 \%-95 \%$ of patients with microadenomas and $40 \%-68 \%$ of patients with noninvasive macroadenomas. ${ }^{68,73-77}$ In patients with invasive pituitary adenomas, a partial removal of tumor replaces the radical operation. ${ }^{68,74}$ For microadenomas, the cure rate by surgery is already high, so the presurgical SA treatment increases the cure rate slightly but not significantly. ${ }^{63}$ For invasive adenomas, although tumor shrinkage was observed in most studies, the long-term biological control of serum GH and IGF-1 levels could not be achieved. ${ }^{64}$ In the study of Mao et al, a higher rate of biochemical cure was observed in patients with presurgical SA treatment in 1-3-month follow-ups; ${ }^{78}$ however, this may have resulted from the cumulative effect of presurgical SA rather than from an actual increase of total resection. Considering the high cure rate of microadenomas by surgery and the difficulties of total resection for invasive macroadenomas, even with presurgical SA treatment, the assumption that a more satisfactory surgical outcome of noninvasive macroadenomas could be achieved through tumor shrinkage resulting from the presurgical SA treatment is reasonable.

\section{Comparison of lanreotide ATG and octreotide LAR}

As mentioned in the guidelines of Melmed et al, in welldesigned trials, the current long-acting SAs, lanreotide ATG and octreotide LAR, show equivalence in their control of symptoms and no significant difference in their ability to normalize serum GH and IGF-1. ${ }^{14}$ Although a number of studies concerning presurgical treatment with lanreotide ATG or octreotide LAR exist, there are few prospective large-scale randomized trials comparing the effects of lanreotide ATG and octreotide LAR, and thus no definite conclusion has yet been achieved. ${ }^{62,64,67,69,70,78}$ Lanreotide ATG and octreotide LAR may therefore have similar effects in clinic according to the current data.

\section{Different strategies: primary and secondary therapy}

Medical treatment with long-acting SA allows for convenient application and shows potential advantages in controlling serum GH and IGF-1 levels; however, the cost-benefit effects of SA treatment should be carefully considered, whether intended as primary or secondary therapy. The indications of SA for acromegaly management recommended in the 2009 guidelines of Melmed et al are as follows: low probability of surgical cure; failure to control serum GH and IGF-1 surgically; and the aim of improving severe perioperative comorbidities before surgery and maintain disease control between each two adjacent administrations of radiation treatment. ${ }^{14}$ That is to say, both primary and secondary SA treatments are suggested in appropriate conditions. In the investigation by Giustina et al, the data showed that neurosurgery was the treatment of choice, for microadenomas and macroadenomas with compression to the optic nerve, in most pituitary adenoma centers in the world. ${ }^{79}$ Further, SAs were chosen as the primary treatment in the condition of macroadenomas with lateral extensions. ${ }^{79}$ In this case, both primary SA therapy and secondary SA therapy following surgery debulking were optional. ${ }^{80}$ Increased response percentage of patients with secondary lanreotide was found if more than 75\% tumor debulking was achieved. ${ }^{17}$ Prospective trials comparing secondary SA treatment following surgery and primary SA treatment are few, although both therapies have been proven effective in the treatment of GH-secreting pituitary adenoma ${ }^{17,80}$

\section{Drug combinations}

As the only GHRA available, pegvisomant has shown its effectiveness in the control of IGF-1.$^{81}$ Recent studies have shown that the combination of SA and pegvisomant in patients who could not achieve IGF-1 normalization was safe and aided improved quality of life in acromegaly. ${ }^{82-85}$ Further, the combination of pegvisomant and SA could reduce the dose of SA that is required. ${ }^{84}$ There is, however, no evidence adequate to prove the significant benefits obtained from combination. ${ }^{84}$ In Melmed et al's guidelines, such combination is recommended on the condition that patients are resistant to other treatments. ${ }^{14}$ In combination with cabergoline, the combination of SA and cabergoline might provide effective treatment in patients with mixed pituitary adenomas in whom simultaneously elevated 


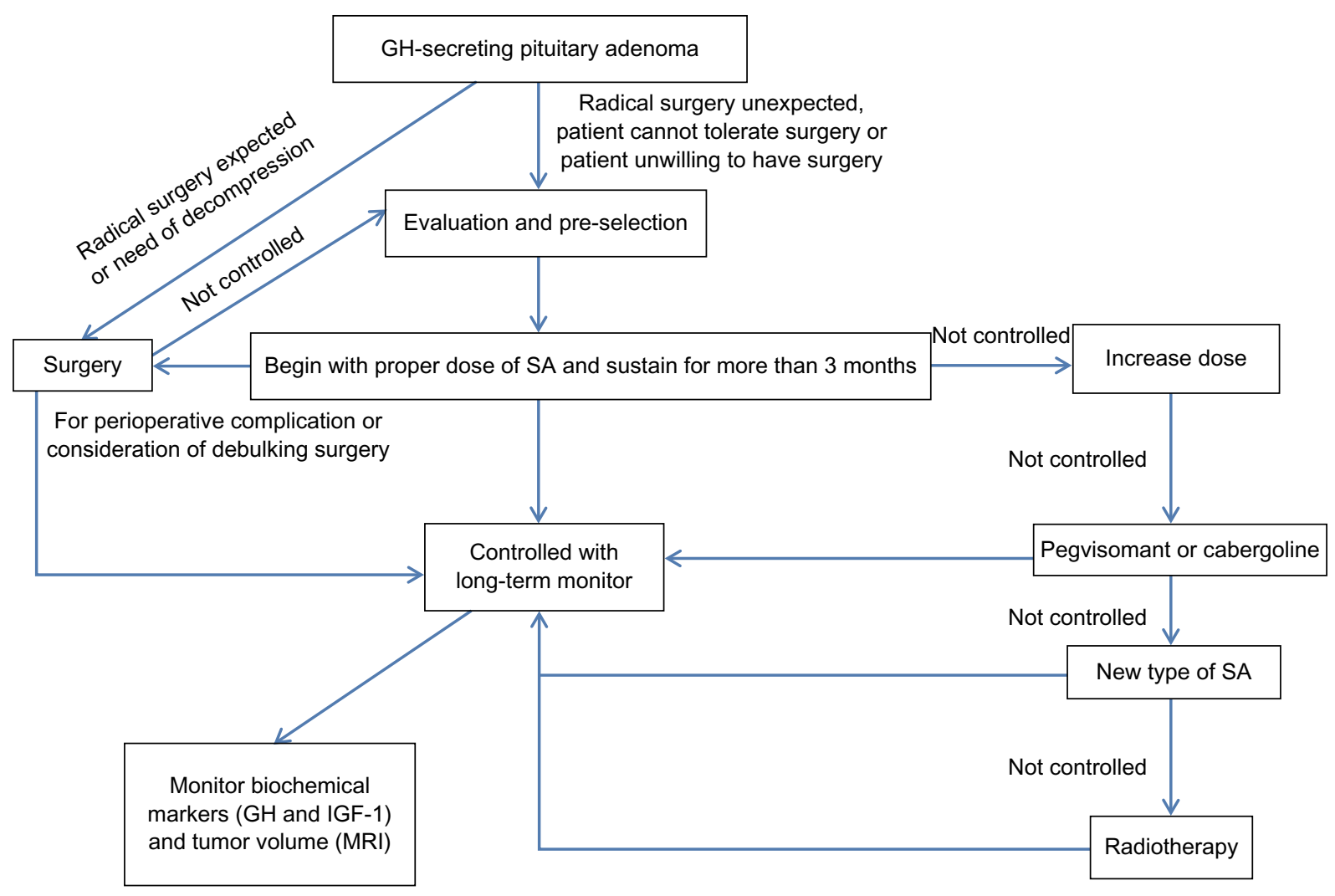

Figure I Proposed treatment strategy for patients with acromegaly.

Abbreviations: GH, growth hormone; IGF-I, insulin-like growth factor I; MRI, magnetic resonance imaging; SA, somatostatin analog.

prolactin ( PRL) and GH are observed, ${ }^{86}$ while, in patients who are partially responsive to the maximum SA dose, additive therapy with cabergoline could normalize IGF-1 in about half of the patients, including those without prolactinemia. ${ }^{32}$

\section{New SAs}

Pasireotide, as a new $\mathrm{SA},{ }^{33}$ is reported to show high affinity to SSTR 1, 2, 3, and $5 .{ }^{87}$ Therefore, it has the potential to be effective in the control of GH, IGF-1, and tumor volume, as shown in a long-term trial investigating the efficacy and safety of pasireotide in acromegaly (Phase II extension study), ${ }^{88}$ and pasireotide is expected in the treatment of Cushing's disease. ${ }^{89}$ There is, however, no evidence proving that pasireotide is valuable when the tumors are resistant to other SAs, despite its special utility in treating tumors resistant to SSTR 2-preferential analogs, which is owing to its high-affinity binding to SSTR 1, 2, 3, and 5. ${ }^{90,91}$ Dopastatin (BIM23A760) is reported to bind to SSTR 2 and 5 and dopamine D2(DAD2) compound, and somatropin (DG3173) is a novel SA with additional binding to SSTR 4 and low insulin-suppressing activity in preclinical studies; these SAs are therefore expected to be effective and supplementary in the treatment of acromegaly with octreotide and lanreotide. ${ }^{92-94}$

\section{SAs in the treatment of gigantism}

For the treatment of gigantism, the optimal choices include transsphenoidal surgery, medical therapy, and radiation therapy. ${ }^{3}$ In the case of microadenomas and wellcircumscribed macroadenomas, transsphenoidal surgery may provide a curative effect. ${ }^{95}$ Radiation therapy can induce the normalization of $\mathrm{GH}$, but the rate of hypopituitarism after treatment is high. ${ }^{3}$ In recent years, the development of longacting SAs has provided a highly effective method by which to control serum GH and normalize IGF-1. ${ }^{6,7}$ Lanreotide or octreotide as the primary therapy, ${ }^{7}$ or combined with surgery, ${ }^{6}$ are effective and safe for gigantism. However, the numbers of patients were limited in the studies concerning medical treatment of gigantism, ${ }^{6-8}$ so conclusions concerning the effect of medical treatment for gigantism are still unclear.

\section{Conclusion}

Long-acting lanreotide and octreotide provide an effective medical treatment whether as primary or secondary therapy for the treatment of GH-secreting pituitary adenoma. Following the development of therapeutic strategies for GHsecreting pituitary adenoma, better prognosis with higher control rates of serum GH and IGF-1 has been achieved. 
Considering, however, the high cost of SA drugs, several points should be considered before medical treatment. A proposed strategy of treatment for patients with acromegaly is summarized in Figure 1. The complete assessment of medical treatment should contain the observation of clinical predictors and preselection, if necessary. To achieve a long-term stable blood concentration, a treatment process of more than 3 months should be implemented. Although controversy regarding presurgical adjuvant therapy exists, more satisfactory surgical outcomes of noninvasive macroadenomas may be achieved. Primary and secondary therapy of SA treatment show no obvious differences with limited data. Thus, in conclusion, a individualized treatment program should be established for each patient after a full evaluation of the risks and benefits to achieve maximum effectiveness with minimum costs.

\section{Acknowledgments}

This research was supported in part by two grants from the National Natural Science Foundation of China (No 41076092, 30971538) and one grant from the Guangdong Provincial 125 key laboratory foundation of medicine (K970401302).

\section{Disclosure}

The authors report no conflicts of interest in this work.

\section{References}

1. Melmed S. Medical progress: acromegaly. $N$ Engl J Med. 2006; 355(24):2558-2573.

2. Raappana A, Koivukangas J, Ebeling T, Pirila T. Incidence of pituitary adenomas in Northern Finland in 1992-2007. J Clin Endocrinol Metab. 2010;95(9):4268-4275.

3. Eugster EA, Pescovitz O. Gigantism. J Clin Endocrinol Metab. 1999;84(12):4379-4384.

4. Etxabe J, Gaztambide S, Latorre P, Vazquez JA. Acromegaly: an epidemiological study. J Endocrinol Invest. 1993;16(3):181-187.

5. Gelber SJ, Heffez DS, Donohoue PA. Pituitary gigantism caused by growth hormone excess from infancy. J Pediatr. 1992;120(6): 931-934

6. Colao A, Pivonello R, Di Somma C, Tauchmanovà L, Savastano S, Lombardi G. Growth hormone excess with onset in adolescence: clinical appearance and long-term treatment outcome. Clin Endocrinol (Oxf). 2007;66(5):714-722

7. Shimatsu A, Teramoto A, Hizuka N, Kitai K, Ramis J, Chihara K. Efficacy, safety, and pharmacokinetics of sustained-release lanreotide (lanreotide Autogel) in Japanese patients with acromegaly or pituitary gigantism. Endocr J. 2013;60(5):651-663.

8. Näntö-Salonen K, Koskinen P, Sonninen P, Toppari J. Suppression of GH secretion in pituitary gigantism by continuous subcutaneous octreotide infusion in a pubertal boy. Acta Paediatr. 1999;88(1):29-33.

9. Melmed S. Acromegaly pathogenesis and treatment. J Clin Invest. 2009;119(11):3189-3202.

10. Anderson D, Faber P, Marcovitz S, Hardy J, Lorenzetti D. Pituitary tumors and the ophthalmologist. Ophthalmology. 1983;90(11): $1265-1270$.
11. Arafah BM, Prunty D, Ybarra J, Hlavin ML, Selman WR. The dominant role of increased intrasellar pressure in the pathogenesis of hypopituitarism, hyperprolactinemia, and headaches in patients with pituitary adenomas. J Clin Endocrinol Metab. 2000;85(5):1789-1793.

12. Colao A, Ferone D, Marzullo P, Lombardi G. Systemic complications of acromegaly: epidemiology, pathogenesis, and management. Endocr Rev. 2004;25(1):102-152.

13. Holdaway IM, Rajasoorya RC, Gamble GD. Factors influencing mortality in acromegaly. $J$ Clin Endocrinol Metab. 2004;89(2): 667-674.

14. Melmed S, Colao A, Barkan A, et al; Acromegaly Consensus Group. Guidelines for acromegaly management: an update. J Clin Endocrinol Metab. 2009;94(5):1509-1517.

15. Alexopoulou O, Bex M, Abs R, T'Sjoen G, Velkeniers B, Maiter D. Divergence between growth hormone and insulin-like growth factor-i concentrations in the follow-up of acromegaly. J Clin Endocrinol Metab. 2008;93(4):1324-1330.

16. Holdaway IM, Bolland MJ, Gamble GD. A meta-analysis of the effect of lowering serum levels of GH and IGF-I on mortality in acromegaly. Eur J Endocrinol. 2008;159(2):89-95.

17. Colao A, Attanasio R, Pivonello R, et al. Partial surgical removal of growth hormone-secreting pituitary tumors enhances the response to somatostatin analogs in acromegaly. J Clin Endocrinol Metab. 2006; 91(1):85-92.

18. Petrossians P, Borges-Martins L, Espinoza C, et al. Gross total resection or debulking of pituitary adenomas improves hormonal control of acromegaly by somatostatin analogs. Eur J Endocrinol. 2005; 152(1):61-66.

19. Jenkins PJ, Bates P, Carson MN, Stewart PM, Wass J. Conventional pituitary irradiation is effective in lowering serum growth hormone and insulin-like growth factor-I in patients with acromegaly. $J$ Clin Endocrinol Metab. 2006;91(4):1239-1245.

20. Maiza JC, Vezzosi D, Matta M, et al. Long-term (up to 18 years) effects on GH/IGF-1 hypersecretion and tumour size of primary somatostatin analogue (SSTa) therapy in patients with GH-secreting pituitary adenoma responsive to SSTa. Clin Endocrinol (Oxf). 2007;67(2): $282-289$.

21. Lucas T, Astorga R; Spanish-Portuguese Multicentre Autogel Study Group on Acromegaly. Efficacy of lanreotide Autogel administered every $4-8$ weeks in patients with acromegaly previously responsive to lanreotide microparticles $30 \mathrm{mg}$ : a phase III trial. Clin Endocrinol (Oxf). 2006;65(3):320-326.

22. Caron P, Beckers A, Cullen DR, et al. Efficacy of the new long-acting formulation of lanreotide (lanreotide Autogel) in the management of acromegaly. J Clin Endocrinol Metab. 2002;87(1):99-104.

23. Caron P, Bex M, Cullen DR, et al; Group for Lanreotide Autogel Long-Term Study on Acromegaly. One-year follow-up of patients with acromegaly treated with fixed or titrated doses of lanreotide Autogel. Clin Endocrinol (Oxf). 2004;60(6):734-740.

24. Gutt B, Bidlingmaier M, Kretschmar K, Dieterle C, Steffin B, Schopohl J. Four-year follow-up of acromegalic patients treated with the new long-acting formulation of Lanreotide (Lanreotide Autogel). Exp Clin Endocrinol Diabetes. 2005;113(3):139-144.

25. Caron P, Morange-Ramos I, Cogne M, Jaquet P. Three year follow-up of acromegalic patients treated with intramuscular slow-release lanreotide. J Clin Endocrinol Metab. 1997;82(1):18-22.

26. Murray RD, Melmed S. A critical analysis of clinically available somatostatin analog formulations for therapy of acromegaly. $J$ Clin Endocrinol Metab. 2008;93(8):2957-2968.

27. Andries M, Glintborg D, Kvistborg A, Hagen C, Andersen M. A 12-month randomized crossover study on the effects of lanreotide Autogel and octreotide long-acting repeatable on GH and IGF-I in patients with acromegaly. Clin Endocrinol (Oxf). 2008;68(3):473-480.

28. van der Lely AJ, Biller BM, Brue T, et al. Long-term safety of pegvisomant in patients with acromegaly: comprehensive review of 1288 subjects in ACROSTUDY. J Clin Endocrinol Metab. 2012;97(5): $1589-1597$. 
29. Feenstra J, de Herder WW, ten Have S, et al. Combined therapy with somatostatin analogues and weekly pegvisomant in active acromegaly. Lancet. 2005;365(9471):1644-1646.

30. Neggers SJ, de Herder WW, Janssen JA, Feelders RA, van der Lely AJ. Combined treatment for acromegaly with long-acting somatostatin analogs and pegvisomant: long-term safety for up to 4.5 years (median 2.2 years) of follow-up in 86 patients. Eur J Endocrinol. 2009;160(4): $529-533$.

31. Abs R, Verhelst J, Maiter D, et al. Cabergoline in the treatment of acromegaly: a study in 64 patients. J Clin Endocrinol Metab. 1998;83(2): 374-378.

32. Sandret L, Maison P, Chanson P. Place of cabergoline in acromegaly: a meta-analysis. J Clin Endocrinol Metab. 2011;96(5):1327-1335.

33. Colao A, Auriemma RS, Lombardi G, Pivonello R. Resistance to somatostatin analogs in acromegaly. Endocr Rev. 2011;32(2):247-271.

34. Newman CB, Melmed S, Snyder PJ, et al. Safety and efficacy of longterm octreotide therapy of acromegaly: results of a multicenter trial in 103 patients - a clinical research center study. J Clin Endocrinol Metab. 1995;80(9):2768-2775.

35. Bevan JS, Atkin SL, Atkinson AB, et al. Primary medical therapy for acromegaly: an open, prospective, multicenter study of the effects of subcutaneous and intramuscular slow-release octreotide on growth hormone, insulin-like growth factor-I, and tumor size. J Clin Endocrinol Metab. 2002;87(10):4554-4563.

36. Reubi JC, Landolt AM. The growth hormone responses to octreotide in acromegaly correlate with adenoma somatostatin receptor status. J Clin Endocrinol Metab. 1989;68(4):844-850.

37. Colao A, Auriemma RS, Rebora A, et al. Significant tumour shrinkage after 12 months of lanreotide Autogel-120 mg treatment given first-line in acromegaly. Clin Endocrinol (Oxf). 2009;71(2):237-245.

38. Hofland LJ, Lamberts SW. The pathophysiological consequences of somatostatin receptor internalization and resistance. Endocr Rev. 2003;24(1):28-47.

39. Bertherat J, Chanson P, Dewailly D, et al. Somatostatin receptors, adenylate cyclase activity, and growth hormone $(\mathrm{GH})$ response to octreotide in GH-secreting adenomas. J Clin Endocrinol Metab. 1993; 77(6):1577-1583.

40. Colao A, Pivonello R, Cappabianca P, et al. Effect of gender and gonadal status on the long-term response to somatostatin analogue treatment in acromegaly. Clin Endocrinol (Oxf). 2005;63(3):342-349.

41. Colao A, Pivonello R, Spinelli L, et al. A retrospective analysis on biochemical parameters, cardiovascular risk and cardiomyopathy in elderly acromegalic patients. J Endocrinol Invest. 2007;30(6):497-506.

42. Colao A, Ferone D, Lastoria S, et al. Prediction of efficacy of octreotide therapy in patients with acromegaly. J Clin Endocrinol Metab. 1996; 81(6):2356-2362.

43. Karavitaki N, Botusan I, Radian S, Coculescu M, Turner HE, Wass JA. The value of an acute octreotide suppression test in predicting longterm responses to depot somatostatin analogues in patients with active acromegaly. Clin Endocrinol (Oxf). 2005;62(3):282-288.

44. Lamberts SW, Uitterlinden P, Schuijff PC, Klijn JG. Therapy of acromegaly with sandostatin: the predictive value of an acute test, the value of serum somatomedin-C measurements in dose adjustment and the definition of a biochemical 'cure'. Clin Endocrinol (Oxf). 1988;29(4): 411-420.

45. Freda PU, Katznelson L, van der Lely AJ, Reyes CM, Zhao SH, Rabinowitz D. Long-acting somatostatin analog therapy of acromegaly: a meta-analysis. J Clin Endocrinol Metab. 2005;90(8):4465-4473.

46. Plöckinger U, Bäder M, Hopfenmüller W, Saeger W, Quabbe HJ. Results of somatostatin receptor scintigraphy do not predict pituitary tumor volume- and hormone-response to octreotide therapy and do not correlate with tumor histology. Eur J Endocrinol. 1997;136(4): 369-376.

47. Legovini P, De Menis E, Billeci D, Conti B, Zoli P, Conte N. 111 Indium-pentetreotide pituitary scintigraphy and hormonal responses to octreotide in acromegalic patients. J Endocrinol Invest. 1997;20(7):424-428.
48. Goerges R, Bockisch A, Cordes U, et al. Correlation between pituitary In-111-pentetreotide uptake and growth hormone $(\mathrm{GH})$ response to octreotide in acromegaly. Eur J Endocrinol. 1996;26(Suppl 1):A55.

49. Cendros JM, Peraire C, Trocóniz IF, Obach R. Pharmacokinetics and population pharmacodynamic analysis of lanreotide Autogel. Metabolism. 2005;54(10):1276-1281.

50. Bronstein M, Musolino N, Jallad R, et al. Pharmacokinetic profile of lanreotide Autogel in patients with acromegaly after four deep subcutaneous injections of 60,90 or $120 \mathrm{mg}$ every 28 days. Clin Endocrinol (Oxf). 2005;63(5):514-519.

51. Astruc B, Marbach P, Bouterfa H, et al. Long-acting octreotide and prolonged-release lanreotide formulations have different pharmacokinetic profiles. J Clin Pharmacol. 2005;45(7):836-844.

52. Croxtall JD, Scott LJ. Lanreotide Autogel: a review of its use in the management of acromegaly. Drugs. 2008;68(5):711-723.

53. Caron P. [Somatuline(R) Autogel(R), a new formulation of lanreotide for the treatment of acromegalic patients]. Ann Endocrinol (Paris). 2002;63(2 Pt 3):2S19-2S24. French.

54. Annamalai AK, Webb A, Kandasamy N, et al. A comprehensive study of clinical, biochemical, radiological, vascular, cardiac, and sleep parameters in an unselected cohort of patients with acromegaly undergoing presurgical somatostatin receptor ligand therapy. J Clin Endocrinol Metab. 2013;98(3):1040-1050.

55. Ben-Shlomo A, Melmed S. Clinical review 154: The role of pharmacotherapy in perioperative management of patients with acromegaly. J Clin Endocrinol Metab. 2003;88(3):963-968.

56. Seidman PA, Kofke WA, Policare R, Young M. Anaesthetic complications of acromegaly. Br J Anaesth. 2000;84(2):179-182.

57. Colao A, Ferone D, Cappabianca P, et al. Effect of octreotide pretreatment on surgical outcome in acromegaly. J Clin Endocrinol Metab. 1997;82(10):3308-3314.

58. Manelli F, Desenzani P, Boni E, et al. Cardiovascular effects of a single slow release lanreotide injection in patients with acromegaly and left ventricular hypertrophy. Pituitary. 1999;2(3):205-210.

59. Hoogwerf BJ. Postoperative management of the diabetic patient. Med Clin North Am. 2001;85(5):1213-1228.

60. Couture E, Bongard V, Maiza JC, Bennet A, Caron P. Glucose status in patients with acromegaly receiving primary treatment with the somatostatin analog lanreotide. Pituitary. 2012;15(4):518-525.

61. Steffin B, Gutt B, Bidlingmaier M, Dieterle C, Oltmann F, Schopohl J. Effects of the long-acting somatostatin analogue Lanreotide Autogel on glucose tolerance and insulin resistance in acromegaly. Eur $J$ Endocrinol. 2006;155(1):73-78.

62. Pita-Gutierrez F, Pertega-Diaz S, Pita-Fernandez S, et al. Place of preoperative treatment of acromegaly with somatostatin analog on surgical outcome: a systematic review and meta-analysis. PLoS One. 2013;8:e61523.

63. Abe T, Lüdecke DK. Effects of preoperative octreotide treatment on different subtypes of $90 \mathrm{GH}$-secreting pituitary adenomas and outcome in one surgical centre. Eur J Endocrinol. 2001;145(2): $137-145$

64. Shen M, Shou X, Wang Y, et al. Effect of presurgical long-acting octreotide treatment in acromegaly patients with invasive pituitary macroadenomas: a prospective randomized study. Endocr J. 2010;57(12): $1035-1044$

65. Colao A. The importance of presurgical somatostatin analogue therapy in acromegaly. Endokrynol Pol. 2007;58(4):356-360.

66. Losa M, Mortini P, Urbaz L, Ribotto P, Castrignanó T, Giovanelli M. Presurgical treatment with somatostatin analogs in patients with acromegaly: effects on the remission and complication rates. J Neurosurg. 2006;104(6):899-906.

67. Oshino S, Saitoh Y, Kasayama S, et al. Short-term preoperative octreotide treatment of GH-secreting pituitary adenoma: Predictors of tumor shrinkage. Endocr J. 2006;53(1):125-132.

68. Ludecke DK, Abe T. Transsphenoidal microsurgery for newly diagnosed acromegaly: a personal view after more than 1,000 operations. Neuroendocrinology. 2006;83(3-4):230-239. 
69. Yin J, Su CB, Xu ZQ, et al. Effect of preoperative use of long-acting octreotide on growth hormone secreting pituitary adenoma and transsphenoidal surgery. Chin Med Sci J. 2005;20(1):23-26.

70. Plöckinger U, Quabbe HJ. Presurgical octreotide treatment in acromegaly: no improvement of final growth hormone $(\mathrm{GH})$ concentration and pituitary function. A long-term case-control study. Acta Neurochir (Wien). 2005;147(5):485-493.

71. Lucas T, Astorga R, Catalá M; Spanish Multicentre Lanreotide Study Group on Acromegaly. Preoperative lanreotide treatment for GHsecreting pituitary adenomas: effect on tumour volume and predictive factors of significant tumour shrinkage. Clin Endocrinol (Oxf). 2003; 58(4):471-481.

72. Stevenaert A, Beckers A. Presurgical Octreotide: treatment in acromegaly. Metabolism. 1996;45(8 Suppl 1):72-74.

73. De P, Rees DA, Davies N, et al. Transsphenoidal surgery for acromegaly in wales: results based on stringent criteria of remission. J Clin Endocrinol Metab. 2003;88(8):3567-3572.

74. Nomikos P, Buchfelder M, Fahlbusch R. The outcome of surgery in 668 patients with acromegaly using current criteria of biochemical 'cure'. Eur J Endocrinol. 2005;152(3):379-387.

75. Kaltsas GA, Isidori AM, Florakis D, et al. Predictors of the outcome of surgical treatment in acromegaly and the value of the mean growth hormone day curve in assessing postoperative disease activity. $J$ Clin Endocrinol Metab. 2001;86(4):1645-1652.

76. Shimon I, Cohen ZR, Ram Z, Hadani M. Transsphenoidal surgery for acromegaly: endocrinological follow-up of 98 patients. Neurosurgery. 2001;48(6):1239-1243; discussion 1244-1245.

77. Beauregard C, Truong U, Hardy J, Serri O. Long-term outcome and mortality after transsphenoidal adenomectomy for acromegaly. Clin Endocrinol (Oxf). 2003;58(1):86-91.

78. Mao ZG, Zhu YH, Tang HL, et al. Preoperative lanreotide treatment in acromegalic patients with macroadenomas increases short-term postoperative cure rates: a prospective, randomised trial. Eur J Endocrinol. 2010;162(4):661-666.

79. Giustina A, Bronstein MD, Casanueva FF, et al. Current management practices for acromegaly: an international survey. Pituitary. 2011;14(2): 125-133.

80. Grasso LF, Pivonello R, Colao A. Somatostatin analogs as a first-line treatment in acromegaly: when is it appropriate? Curr Opin Endocrinol Diabetes Obes. 2012;19(4):288-294.

81. Neggers SJ, van Aken MO, de Herder WW, et al. Quality of life in acromegalic patients during long-term somatostatin analog treatment with and without pegvisomant. J Clin Endocrinol Metab. 2008;93(10): 3853-3859.

82. Fendri S, Karaca P, Tiev E, Buchfelder M, Lalau J. Control of disease activity and tumor size after introduction of pegvisomant in a lanreotideresistant acromegalic patient. Ann Endocrinol (Paris). 2013;74(1): 49-52.
83. Neggers SJ, de Herder WW, Feelders RA, van der Lely AJ. Conversion of daily pegvisomant to weekly pegvisomant combined with long-acting somatostatin analogs, in controlled acromegaly patients. Pituitary. 2011;14(3):253-258.

84. Madsen M, Poulsen PL, Orskov H, Møller N, Jørgensen JO. Cotreatment with pegvisomant and a somatostatin analog (SA) in SA-responsive acromegalic patients. J Clin Endocrinol Metab. 2011; 96(8):2405-2413.

85. van der Lely A, Bernabeu I, Cap J, et al. Coadministration of lanreotide Autogel and pegvisomant normalizes IGF1 levels and is well tolerated in patients with acromegaly partially controlled by somatostatin analogs alone. Eur J Endocrinol. 2011;164(3):325-333.

86. Sowiński J, Sawicka N, Piatek K, Zybek A, Ruchala M. Pharmacoeconomic aspects of the treatment of pituitary gland tumours. Contemp Oncol (Pozn). 2013;17(2):137-143.

87. Lewis I, Bauer W, Albert R, et al. A novel somatostatin mimic with broad somatotropin release inhibitory factor receptor binding and superior therapeutic potential. J Med Chem. 2003;46(12): 2334-2344.

88. Petersenn S, Farrall AJ, Block C, et al. Long-term efficacy and safety of subcutaneous pasireotide in acromegaly: results from an open-ended, multicenter, Phase II extension study. Pituitary. Epub March 26, 2013.

89. Colao A, Petersenn S, Newell-Price J, et al. A 12-month phase 3 study of pasireotide in Cushing's disease. $N$ Engl J Med. 2012;366(10): 914-924.

90. Hofland LJ, van der Hoek J, van Koetsveld PM, et al. The novel somatostatin analog SOM230 is a potent inhibitor of hormone release by growth hormone- and prolactin-secreting pituitary adenomas in vitro. J Clin Endocrinol Metab. 2004;89(4):1577-1585.

91. Murray RD, Kim K, Ren SG, et al. The novel somatostatin ligand (SOM230) regulates human and rat anterior pituitary hormone secretion. J Clin Endocrinol Metab. 2004;89(6):3027-3032.

92. Gruszka A, Culler MD, Melmed S. Somatostatin analogs and chimeric somatostatin-dopamine molecules differentially regulate human growth hormone and prolactin gene expression and secretion in vitro. $\mathrm{Mol}$ Cell Endocrinol. 2012;362(1-2):104-109.

93. Cuny T, Mohamed A, Graillon T, et al. Somatostatin receptor sst2 gene transfer in human prolactinomas in vitro: impact on sensitivity to dopamine, somatostatin and dopastatin, in the control of prolactin secretion. Mol Cell Endocrinol. 2012;355(1):106-113.

94. Plöckinger U, Hoffmann U, Geese M, et al. DG3173 (somatoprim), a unique somatostatin receptor subtypes 2-, 4- and 5-selective analogue, effectively reduces $\mathrm{GH}$ secretion in human $\mathrm{GH}$-secreting pituitary adenomas even in Octreotide non-responsive tumours. Eur J Endocrinol. 2012;166(2):223-234.

95. Lu PW, Silink M, Johnston I, Cowell CT, Jimenez M. Pituitary gigantism. Arch Dis Child. 1992;67(8).
Patient Preference and Adherence

\section{Publish your work in this journal}

Patient Preference and Adherence is an international, peer-reviewed, open access journal focusing on the growing importance of patient preference and adherence throughout the therapeutic continuum. Patient satisfaction, acceptability, quality of life, compliance, persistence and their role in developing new therapeutic modalities and compounds to

\section{Dovepress}

optimize clinical outcomes for existing disease states are major areas of interest. This journal has been accepted for indexing on PubMed Central. The manuscript management system is completely online and includes a very quick and fair peer-review system. Visit http://www.dovepress.com/ testimonials.php to read real quotes from published authors. 